\title{
Colonic diverticular bleeding: Urgent colonoscopy without purging and endoscopic treatment with epinephrine and hemoclips
}

\author{
Ignacio Couto-Worner, Benito González-Conde, Emilio Estévez-Prieto and Pedro Alonso-Aguirre
}

Department of Gastroenterology. Complexo Hospitalario Universitario de A Coruña. A Coruña, Spain

\begin{abstract}
Diverticular disease is the most frequent cause of lower gastrointestinal bleeding. Most of the times, bleeding stops without any intervention but in 10-20\% of the cases it is necessary to treat the hemorrhage. Several modalities of endoscopic treatment have been described after purging the colon. We present five cases of severe diverticular bleeding treated with injection of epinephrine and hemoclips. All the colonoscopies were performed without purging of the colon in an emergency setting, with correct visualization of the point of bleeding. Patients recovered well avoiding other aggressive procedures such as angiography or surgery.
\end{abstract}

Key words: Lower gastrointestinal bleeding. Diverticular bleeding. Diverticulosis. Hemoclip.

\section{INTRODUCTION}

Diverticular disease of the colon is the most frequent cause of severe lower gastrointestinal bleeding, ahead of angiodysplasia (1). In approximately $80 \%$ of cases, bleeding stops spontaneously without any intervention. Conservative management has traditionally been used for diverticular bleeding, carrying out surgery or angiography when necessary. In recent years, several studies have defended the use of urgent colonoscopy after purging the colon because of its higher diagnostic rate $(2,3)$, shorter hospital stay and lower morbidity rate with respect to angiography and surgery (4).

Several endoscopic techniques have been described to treat diverticular bleeding, including the injection of epi-

Received: 14-02-2013

Acepted: 16-04-2013

Correspondence: Ignacio Couto-Worner. Department of Gastroenterology. Complexo Hospitalario Universitario de A Coruña. As Xubias de Arriba, 84. 15006 A Coruña, Spain

e-mail: ignacio.couto.worner@sergas.es nephrine (5), contact thermal therapy (6), fibrin sealant (7), hemoclips $(8,9)$ or band ligation (10).

We present a series of five patients with severe lower gastrointestinal bleeding treated between 2007 and 2010. They underwent urgent colonoscopy without bowel cleansing with Olympus endoscopes. Explorations were performed by non-resident endoscopists assisted with a nurse from the Gastroenterology Unit. Air was insufflated and liquid, hematic rests and small clots were aspired alternatively. We paid more attention to the parts of the colon with fresh blood. We used a water pump for a better visualization of the mucosa and to wash segments with blood. All the patients received endoscopic treatment with epinephrine and hemoclips.

\section{CLINICAL CASES}

\section{Case 1}

A 67 year-old healthy male was admitted to the hospital because of diffuse abdominal pain, tenesmus and the presence of blood in his stool. In the emergency department he was hemodynamically stable with a hemoglobin level of $15.7 \mathrm{~g} / \mathrm{dL}$. After 12 hours he presented severe hematochezia with persistent hypotension. An upper source of bleeding was ruled out by an esophagogastroduodenoscopy, so an urgent colonoscopy without preparation was performed. A severe diverticulosis of the left side of the colon was observed and active pulsatile bleeding from the bottom of one of them. Bleeding stopped after injecting epinephrine in a concentration of 1:10,000 around the

Couto-Worner I, González-Conde B, Estévez-Prieto E, AlonsoAguirre PA. Colonic diverticular bleeding: Urgent colonoscopy without purging and endoscopic treatment with epinephrine and hemoclips. Rev Esp Enferm Dig 2013;105:495-498. 
neck of the diverticulum. A hemoclip was then placed at the neck, producing an eversion of the diverticulum and revealing a visible vessel on which another hemoclip was placed. The patient has not relapse during next 46 months.

\section{Case 2}

An 82 year-old female was hospitalized with hematochezia and hemodynamic instability. She had a history of hypertension and a previous episode of lower gastrointestinal bleeding, probably connected with a colonic diverticulosis suffered two years before. An urgent colonoscopy without purging was performed. A diverticulum at the sigma was identified with active bleeding apparently at the neck, which stopped after injecting epinephrine and using three hemoclips. After two days the patient began to bleed, so the colonoscopy was repeated. Two hemoclips remained upon the diverticulum and an adherent clot was dislodged after water irrigation. At the bottom of the diverticulum there was a visible vessel that was occluded by two hemoclips.

\section{Case 3}

A 67 year-old male with a history of a transient ischemic attack, a coronary stent and Leriche syndrome under treatment with clopidogrel was admitted to the hospital. He presented severe hematochezia and an urgent colonoscopy without purging was performed, detecting bleeding from a diverticulum at the splenic flexure. Epinephrine was injected and three hemoclips were placed to close neck, and the bleeding stopped.

\section{Case 4}

A 79 year-old male was admitted to hospital due to orchiepididymitis under treatment with non-steroidal anti-inflammatory drugs and antibiotics. During hospi- talization he presented lower gastrointestinal bleeding and refractory hypotension to resuscitation measures. A gastroscopy ruled out an upper source of bleeding and an urgent colonoscopy without purging was performed. A diverticulum with active bleeding from the bottom was detected in the transverse part of the colon (Fig. 1). After injecting epinephrine, four hemoclips were placed with one prong inside the diverticulum and the other prong outside, adjacent to the colonic mucosa.

\section{Case 5}

A 74-year-old woman with diabetes mellitus and treatment with aspirin came to the emergency department because of severe hematochezia with hypotension. An urgent colonoscopy without purging was performed, and a bleeding diverticulum was identified at the sigmoid colon. Because we could not see the origin of the hemorrhage after injecting epinephrine, we decided to close the diverticulum with 5 hemoclips. Bleeding stopped and did not recur in the following months.

\section{DISCUSSION}

Diverticular bleeding has become the most frequent cause of lower gastrointestinal bleeding (near $40 \%$ ) in Western populations (1). In most cases bleeding stops spontaneously, but around 3-5\% of patients with colonic diverticulosis develop severe bleeding $(11,12)$. There is no clear consensus regarding the management of these patients, with debate between the endoscopic and angiographic approach. Following the study of Jensen et al. (2) urgent colonoscopy has become an important diagnostic and therapeutic tool in severe lower gastrointestinal bleeding, showing a higher diagnostic rate $(2,3)$ and resulting in shorter time to discharge from hospital if colonoscopy is performed in the first hours (4), although not all of the studies agree on this point (13). Most studies defend purging the colon, which would be the ideal situation, although
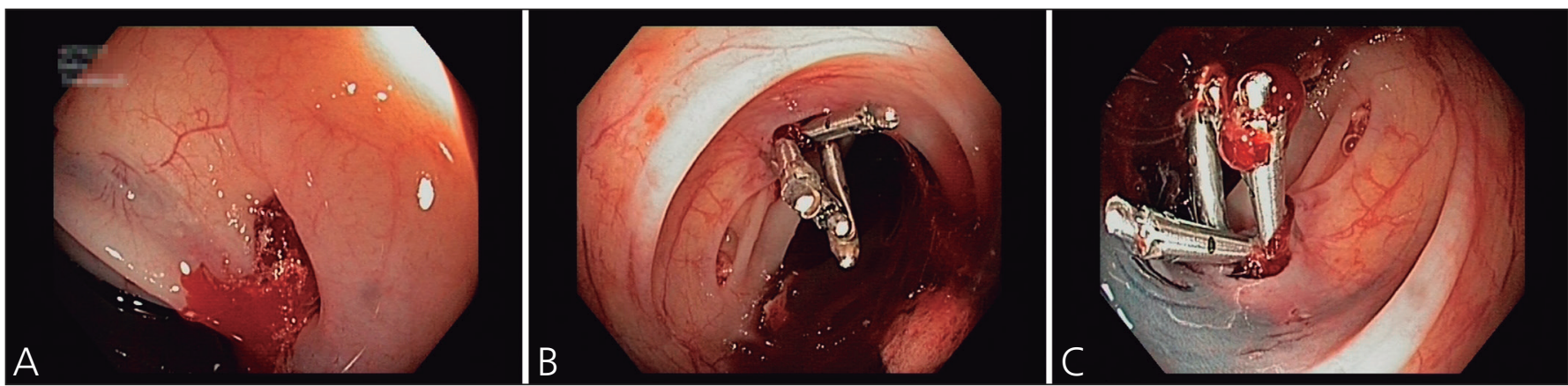

Fig. 1. A. A diverticulum bleeding by the dome at the left side of the colon. B. After placing four hemoclips with one prong inside the diverticulum and the other outside it, bleeding stopped. C. The diverticulum without bleeding, and a tattoo next to it. 
there is no clear consensus on this point (14). If the colon is not clean, the exploration will be more complex and it will be more difficult to find the responsible diverticulum and this, at least theoretically, can increase the risk of perforation.

In the patients included in our series it was not possible to wait for the colon purge because of the urgent clinical situation which meant the colonoscopy had to be carried out without delay. The responsible diverticulum could be located because we believe that active bleeding worked as a cathartic solution to provide a sufficient visualization of the colon, helped by exhaustive washing. If there is no active bleeding it will be more difficult to find signs of hemorrhage such as visible vessels or an adherent clot, so it is very important to clinically select which patients will benefit from an urgent colonoscopy without purging. These patients will be the ones with active bleeding, persistent hematochezia or refractory hypotension. The overall evolution was very favorable, avoiding more aggressive procedures in elderly patients and those with various comorbidities. Even in cases when surgical intervention is needed, colonoscopy can help to guide the surgeon to decide which part of the bowel needs to be removed in order to avoid a potential total colectomy, which has a high morbimortality rate. Furthermore, if the cecum is reached and the cause of bleeding is still not detected, it is possible to attempt to enter the ileum in order to rule out that the source may be in the small intestine.

In our hospital, during the period between 2007 and 2012, we performed 97 urgent colonoscopies because of severe lower gastrointestinal bleeding. We accomplished 83 explorations without cleaning the colon because of the critical clinical situation. From this group, in $39(47 \%)$ we succeeded in identifying the point or the responsible lesion, and in $18(21 \%)$ we could apply and endoscopic treatment.

Another series of patients with diverticular bleeding were treated with other endoscopic techniques. Injecting epinephrine (5) can produce an initial hemostasis due to its vasoconstrictive and mechanical effect, making it possible to carry out definitive treatment with better visualization. We consider epinephrine to be an insufficient treatment on its own. The use of thermal probes can at least theoretically increase the risk of perforation due to the thinness of the diverticular wall, especially when bleeding originates at the bottom of the diverticulum.

Hemoclips have been used in different ways $(8,9)$, depending on whether bleeding comes from the neck or the bottom of the diverticulum. All the hemoclips used in our cases were Resolution ${ }^{\circledR}$ clips (Boston Scientific). In two of the cases in our series, hemostasis was made directly on the point of bleeding, one of them at the top of the diverticulum (Table I). If this is not possible, as occurred in cases 3 and 5, the mouth of the diverticulum can be closed. Another option, as in case 4, which due to its small size meant it was impossible to identify the exact point of bleeding, is to apply the clip with one prong inside and the other prong outside the diverticulum taking in the adjacent mucosa, at the point where the responsible artery is located. We recommend tattooing the mucosa next to the diverticulum should it need to be located in case of re-bleeding, either when attempting to stop it with endoscopy or to guide an eventual surgical resection.

Although no randomized studies exist, we defend the performance of an urgent colonoscopy by an experienced endoscopist in cases of severe lower gastrointestinal bleeding, with purging of the colon if possible. However, if this cannot be delayed due to the failure of resuscitation maneuvers with the suspicion of active bleeding, then an effort should be made to carry it out in order to locate the source of bleeding. In our opinion enemas should be avoided as they could mobilize fresh blood and lead to the loss of the localization reference for the bleeding diverticulum.

Angiography is another alternative, although it has several inconveniences. It requires a blood debit of more than $1 \mathrm{ml} / \mathrm{min}(15)$. In order to detect the point of bleeding angiography must be carried out at the moment of the hemorrhage, and this is often intermittent. Moreover, the use of contrast in elderly patients may cause acute renal failure. The risk of bowel infarction after angiographic embolization appears in around 13-33\% of patients. If the source of bleeding is not identified by endoscopy we can do an angio-computed tomography, with a diagnostic accuracy of 80-85\% (16). This technique can be useful for detecting the origin of bleeding and rule out other lesions and select the patients for arteriography. The choice of the preferred intervention in severe lower gastrointestinal

Table I. Patient characteristics

\begin{tabular}{|c|c|c|c|c|c|c|c|}
\hline Patient & Age & Sex & Site of bleeding & Bleeding point & $\begin{array}{c}\text { Early } \\
\text { bleeding * }\end{array}$ & Surgery & $\begin{array}{l}\text { Follow-up } \\
\text { (months) }\end{array}$ \\
\hline 1 & 67 & $M$ & Left colon & Cuello & No & No & 46 \\
\hline 3 & 67 & M & Splenic flexure & Dome & No & No & 9 \\
\hline 4 & 79 & M & Left colon & Dome & No & No & 6 \\
\hline
\end{tabular}

*Early bleeding defined as the one who took place during the first month. 
bleeding will depend on the availability and experience of each center.

In summary, urgent colonoscopy, with or without purging, and the combination of epinephrine and hemoclips is one of the most useful tools in the management of severe lower gastrointestinal bleeding due to diverticulum of the colon. More studies are needed to define the best diagnostic and therapeutic approach and the optimal moment for it to be performed.

\section{REFERENCES}

1. Elta GH. Urgent colonoscopy for acute lower-GI bleeding. Gastrointest Endosc 2004;59:402-8.

2. Jensen DM, Machicado GA. Diagnosis and treatment of severe hematochezia. The role of urgent colonoscopy after purge. Gastroenterology 1988;95:1569-74.

3. Machicado GA, Jensen DM. Endoscopic diagnosis and treatment of severe lower gastrointestinal bleeding. Indian J Gastroenterol 2006;25(Supl. 1):S43-51.

4. Strate LL. Lower GI bleeding: Epidemiology and diagnosis. Gastroenterol Clin N Am 2005;34:643-64.

5. Ramirez FC, Johnson DA, Zierer ST. Walker GJ, Sanowski RA. Successful endoscopic hemostasis of bleeding colonic diverticula with epinephrine injection. Gastrointest Endosc 1996;43:167-70.
6. Bloomfeld RS, Rockey DC, Shetzline MA. Endoscopic therapy of acute diverticular hemorrhage. Am J Gastroenterol 2001;96:2367-72.

7. Andress HJ, Mewes A, Lange V. Endoscopic hemostasis of a bleeding diverticulum of the sigma with fibrin sealant. Endoscopy 1993;25:193.

8. Hokama A, Uehara T, Nakayoshi T, Uezu Y, Tokuyama K, Kinjo F, et al. Utility of endoscopic hemoclipping for colonic diverticular bleeding. Am J Gastroenterol 1997;92:543-6.

9. Yen EF, Ladabaum U, Muthusamy VR, Cello JP, McQuaid KR, Shah $\mathrm{JN}$. Colonoscopic treatment of acute diverticular hemorrhage using endoclips. Dig Dis Sci 2008:53:2480-5.

10. Farrell JJ, Graeme-Cook F, Kelsey PB. Treatment of bleeding colonic diverticula by endoscopic band ligation: an in-vivo and ex-vivo pilot study. Endoscopy 2003;35:823-9.

11. Stollman N, Raskin JB. Diverticular disease of the colon. Lancet 2004;363:631-9.

12. Strate LL, Syngal S. Timing of colonoscopy: impact on length of hospital stay in patients with acute lower intestinal bleeding. Am J Gastroenterol 2003;98:317-22.

13. Green BT, Rockey DC, Portwood G, Tarnasky PR, Guarisco S, Branch MS, et al. Urgent colonoscopy for evaluation and management of acute lower gastrointestinal hemorrhage: a randomized controlled trial. Am J Gastroenterol 2005;100:2395-402.

14. Farrell JJ, Friedman LS. Review article: The management of lower gastrointestinal bleeding. Aliment Pharmacol Ther 2005;21:1281-98.

15. Zuckerman DA, Bocchini TP, Birnbaum EH. Massive hemorrhage in the lower gastrointestinal tract in adults: diagnostic imaging and intervention. AJR Am J Roentgenol 1993;161:703-11.

16. Martí M, Artigas JM, Garzón G, Álvarez-Sala R, Soto JA. Acute lower intestinal bleeding: feasibility and diagnostic performance of CT angiography. Radiology 20012;262:109-16. 